\title{
Stable Expression and Characterization of Monomeric and Dimeric Recombinant Hybrid-IgG/IgA Immunoglobulins Specific for Shiga Toxin
}

\author{
Koki Iwata, Kohta Kurohane, Katsuhiro Nakanishi, Masaki Miyake, and Yasuyuki Imai* \\ Laboratory of Microbiology and Immunology, University of Shizuoka School of Pharmaceutical Sciences; 52-1 Yada, \\ Suruga-ku, Shizuoka, Shizuoka 422-8526, Japan. \\ Received April 24, 2014; accepted June 21, 2014; advance publication released online July 1, 2014
}

\begin{abstract}
Antigen-specific immunoglobulin A (IgA) may be useful for preventing infectious diseases through passive immunization on the mucosal surface. We previously established mouse IgA and IgG monoclonal antibodies (mAbs) specific for the binding subunit of Shiga toxin 1 (Stx1B). We also developed a recombinant hybrid-IgG/IgA, in which variable regions from the IgG $\mathrm{mAb}$ were present. The binding activity of recombinant hybrid-IgG/IgA was verified by transient expression. Aiming at a constant supply, we established Chinese hamster ovary cells stably expressing monomeric or dimeric hybrid-IgG/IgA. The cDNAs encoding heavy and light chains were co-expressed for the monomeric hybrid-IgG/IgA, while those encoding heavy, light, and joining chains were co-expressed for the dimeric one. Serum-free culture supernatants of the cloned transfectants were subjected to size-exclusion chromatography. The elution patterns showed that the binding to immobilized Stx1B and the immunoblot signals of assembled immunoglobulins were correlated. In the transfectant for the dimeric hybrid-IgG/IgA, both monomers and dimers were observed. Size-exclusion chromatography enabled us to prepare a sample of the dimeric hybrid-IgG/IgA devoid of the monomeric one. The monomeric and dimeric forms of hybrid-IgG/IgA were prepared from the respective transfectants to examine the neutralization of Stx1. After pretreatment with monomeric or dimeric hybrid-IgG/IgA, the cytotoxicity of Stx1 toward Vero cells was abolished. Furthermore, the dimeric form was more than 10-fold more effective than the monomeric one in terms of toxin neutralization. These results suggest that the tetravalent feature of the binding sites of the dimeric hybrid-IgG/IgA contributes to the efficacy of toxin neutralization.
\end{abstract}

Key words recombinant immunoglobulin A; Shiga toxin; neutralization; dimer

Shiga toxin 1 (Stx1) is a virulence factor of enterohaemorrhagic Escherichia coli (EHEC) strains such as O157:H7 and Shigella dysenteriae. ${ }^{1,2)}$ It comprises one A subunit and five B subunits. ${ }^{3)}$ After binding through B subunits (Stx1B), which are cell-binding subunits, Stx1 holotoxins are endocytosed. ${ }^{4}$ The A subunit, which is translocated into the cytoplasm, induces cytotoxicity through dysfunction of ribosomes and inhibition of protein synthesis. ${ }^{5)}$

Immunoglobulin A ( $\operatorname{IgA}$ ) plays a role in the humoral arm of the adaptive immunity on the mucosal surface. ${ }^{6)}$ It is produced by B cells after class switch of heavy $(\mathrm{H})$ chains from IgM to IgA. IgA-producing B cells also produce joining (J) chains that covalently join $\operatorname{IgA}$ monomers to form dimeric $\operatorname{IgA}(\mathrm{dIgA}) .^{7}$ On the mucosal epithelium, the dimeric IgA is transported by polymeric immunoglobulin receptors (pIgR) from the basolateral to the apical side. Dimer formation is required for the binding to $\left.\mathrm{pIgR}{ }^{6}{ }^{6}\right)$ On the mucosal surface, pIgR is cleaved by proteases, and the complex of $\operatorname{dIgA}$ and the ectodomain of $\mathrm{pIgR}$ is secreted onto the mucosal surface. The ectodomain of pIgR is termed a secretory component (SC) in a secretory $\operatorname{Ig} \mathrm{A}(\mathrm{SIg} \mathrm{A})$. SIgA prevents invasion by pathogens and their virulence factors. This function of SIgA is termed immune exclusion. ${ }^{8)}$ In addition, oral access to SIgA, such as through the mother's milk, also protects infants from pathogens. This route contributes to the establishment of passive immunity due to preformed SIgA.

To achieve oral passive immunity against Stx1B, we obtained a mouse $\operatorname{IgA}$ monoclonal antibody $(\mathrm{mAb})$ against Stx1B, termed G2G7, by intranasal immunization. ${ }^{9,10)}$ We also produced an IgG1 mAb against Stx1B, termed D11C6. ${ }^{11)}$ On

The authors declare no conflict of interest. testing of the binding of Stx1B to Burkitt's lymphoma Ramos cells, we found that the IgG1 mAb but not the IgA one completely inhibited the binding of Stx1B to the target cells. ${ }^{11)}$ To obtain an IgA mAb with stronger biological activity, we constructed a recombinant $\mathrm{H}$ chain. Thus, the $\mathrm{H}$ chain variable region and the $\mathrm{CH}_{1}$ domain are from D11C6 (IgG1), while the $\mathrm{CH}_{2} 2$ and $\mathrm{CH} 3$ domains from $\mathrm{G} 2 \mathrm{G} 7$ (IgA). We transiently expressed this hybrid $\mathrm{H}$ chain, the light (L) chain from D11C6 and the $\mathrm{J}$ chain obtained from G2G7 in COS-1 cells to produce hybrid-IgG/IgA. ${ }^{12}$ The hybrid-IgG/IgA formed dimers and inhibited Stx1B binding to Ramos cells as efficiently as D11C6 did. Thus, we were able to establish an antigen-specific recombinant monoclonal dimeric $\operatorname{IgA}$ that inhibits toxin binding to natural ligands on toxin sensitive cells.

In this study, we obtained cell lines producing monomeric and dimeric hybrid-IgG/IgA through stable expression in Chinese hamster ovary $(\mathrm{CHO})$ cells aiming at a sufficient and constant supply of the recombinant IgA. This strategy made it possible for us to demonstrate the toxin neutralization activity of the hybrid-IgG/IgA in comparison with that of IgG1 and IgA mAbs.

\section{MATERIALS AND METHODS}

Reagents Shiga toxin 1 holotoxin (Stx1) and the recombinant purified B subunit of Stx1 (Stx1B) were prepared as described previously. ${ }^{11,13)}$ Stx1B-specific mouse mAb G2G7 $(\operatorname{IgA}, \kappa)$ and mouse mAb D11C6 $(\operatorname{IgG1}, \kappa)$ were prepared as described previously. ${ }^{10,11)}$ The cDNAs encoding the Stx1Bspecific hybrid-IgG/IgA $\mathrm{H}$ chain, IgG1-associated $\mathrm{L}$ chain and $\mathrm{J}$ chain were prepared by subcloning into the pcDNA3.1(+), pcDNA3.1(+)/Hyg and pcDNA3.1(+) Zeo expression vec- 
tors (Life Technologies; Carlsbad, CA, U.S.A.), respectively, as described previously. ${ }^{12)}$ Kanamycin sulfate, hygromycin $\mathrm{B}$ and 2,2'-azinobis(3-ethylbenzothiazoline-6-sulfonic acid) (ABTS) were purchased from Wako Pure Chemical Industries, Ltd. (Osaka, Japan); Dulbecco's modified Eagle's medium (DMEM), Ham's F12 (F12), and medium 199 (M199) from Nissui Pharmaceuticals (Tokyo, Japan); and CD CHO-A medium, Opti-MEM I medium and zeocin from Life Technologies. G418 was purchased from Nacalai Tesque (Kyoto, Japan); fetal bovine serum (FBS) from Hyclone (South Logan, UT, U.S.A.); and myeloma proteins TEPC 15 (IgA, $\kappa$ ) and MOPC 21 (IgG1, $\kappa)$, 2-mercaptoethanol (2-ME), and bovine serum albumin (BSA; Fraction V) from Sigma (St. Louis, MO, U.S.A.); and a Cell Counting Kit-8 from DOJINDO (Kumamoto, Japan). Horseradish peroxidase (HRP)-goat anti-mouse IgA ( $\alpha$ chainspecific) was purchased from Southern Biotech (Birmingham, AL, U.S.A.); HRP-rat anti-mouse $\kappa$ chain and purified rabbit anti-mouse IgA ( $\alpha$ chain-specific) from Zymed (South San Francisco, CA, U.S.A.); Sephacryl S-300 High Resolution, Vivaspin 20-100K and Vivaspin 2-100K from GE Healthcare (Tokyo, Japan); and FuGENE ${ }^{\circledR} 6$ from Roche Diagnostics (Indianapolis, IN, U.S.A.).

Cells CHO-K1 cells and African green monkey kidneyderived Vero cells were obtained from the American Type Culture Collection (Manassas, VA, U.S.A.). CHO-K1 cells were cultured in DMEM/F12 supplemented with 10\% FBS and $60 \mu \mathrm{g} / \mathrm{mL}$ kanamycin (10\% FBS-DMEM/F12). Vero cells were cultured in M199 supplemented with 10\% FBS and $60 \mu \mathrm{g} / \mathrm{mL}$ kanamycin. Cell cultures were performed at $37^{\circ} \mathrm{C}$ under a humidified atmosphere of $5 \% \mathrm{CO}_{2} / 95 \%$ air.

Stable Expression of Hybrid-IgG/IgA CHO-K1 cells were transfected with the plasmid expression vectors for the hybrid-IgG/IgA $\mathrm{H}$ and $\mathrm{L}$ chains (monomeric $\operatorname{IgA}$ ), or those for the hybrid-IgG/IgA H, L and J chains (dimeric $\operatorname{IgA}$ ) by means of FuGENE ${ }^{\circledR} 6$. A total $1 \mu \mathrm{g}$ of plasmid DNA was used to transfect subconfluent $\mathrm{CHO}-\mathrm{K} 1$ cells in $1 \mathrm{~mL}$ of Opti-MEM in the wells of a 12-well plate (Falcon ${ }^{\circledR}$ 353043; Corning Inc., Corning, NY, U.S.A.). Forty-eight hours after transfection, cells were selected in the presence of appropriate antibiotics in $10 \% \mathrm{FBS}-\mathrm{DMEM} / \mathrm{F} 12$. The concentrations of antibiotics were as follows: $800 \mu \mathrm{g} / \mathrm{mL}$ G418, 400 units /mL hygromycin $\mathrm{B}$ and $1000 \mu \mathrm{g} / \mathrm{mL}$ zeocin. The cells producing monomeric or dimeric IgA specific for Stx1B were cloned by limiting dilution in $10 \%$ FBS-DMEM/F12 in the presence of appropriate antibiotics.

Gel Filtration The resulting cloned-CHO-K1 cells that produced recombinant antibodies were cultured in 10\% FBSDMEM/F12 in the presence of appropriate antibiotics. Under subconfluent conditions, the medium was replaced with serum-free CD CHO-A medium, and culture supernatants were harvested after $3 \mathrm{~d}$. Each culture supernatant $(15-30 \mathrm{~mL})$ was concentrated to $1 \mathrm{~mL}$ by means of Vivaspin 20-100K (applicable volume $20 \mathrm{~mL}$, exclusion molecular weight 100000). The concentration and dilution (in phosphate-buffered saline containing $0.02 \% \mathrm{NaN}_{3} ; \mathrm{PBS}-\mathrm{NaN}_{3}$ ) procedures were repeated four times to remove proteins of less than $100 \mathrm{kDa}$. Each concentrated sample $(1 \mathrm{~mL})$ was separated on a column of Sephacryl S-300 $(1.5 \mathrm{~cm} \times 40 \mathrm{~cm})$ equilibrated with $\mathrm{PBS}-\mathrm{NaN}_{3}$. Fractions $\left(1 \mathrm{~mL}\right.$ each) were collected to monitor $\mathrm{OD}_{280 \mathrm{~nm}}$ and binding activity toward immobilized Stx1B.

Sodium Dodecyl Sulfate-Polyacrylamide Gel Electro- phoresis (SDS-PAGE) and Immunoblotting We carried out SDS-PAGE (non-reducing 7.5\% gel and reducing $12 \%$ gel under Laemmli's conditions) and then immunoblotting as described. ${ }^{12)}$ Hybrid-IgG/IgA was detected by $1 \mathrm{~h}$ incubation with HRP-goat anti-mouse $\operatorname{IgA}(1: 1000)$. The signal representing the $\mathrm{H}$ chain was enzymatically detected using a chemiluminescence reagent (West Pico; Thermo Scientific Pierce, Rockford, IL, U.S.A.). As molecular weight standards, Precision Plus Protein WesternC ${ }^{\mathrm{TM}}$ Standards with StrepTactinHRP (Bio-Rad; Hercules, CA, U.S.A.) and MagicMark ${ }^{\mathrm{TM}}$ XP Western Protein Standard (Life Technologies) were used. The bands were directly visualized by means of chemiluminescence.

Enzyme-Linked Immunosorbent Assay (ELISA) The binding of the hybrid-IgG/IgA to immobilized Stx1B was detected with HRP-goat anti-mouse IgA by means of ELISA as described previously. ${ }^{12}$ ) To quantitate total hybrid-IgG/ IgA in samples, sandwich ELISA was performed. ${ }^{12)}$ In this case, immobilized rabbit anti-mouse IgA was used to capture antibodies and HRP-rat anti-mouse $\kappa$ to detect the captured hybrid-IgG/IgA.

Toxin Neutralization Assay Appropriate fractions containing hybrid-IgG/IgA were pooled and the buffer was changed to sterile PBS by means of a Vivaspin $2-100 \mathrm{~K}$ to remove $\mathrm{NaN}_{3}$, followed by sterilization by membrane filtration. The concentrations of monoclonal antibodies (mAbs) were determined by sandwich ELISA as described previously. ${ }^{10,11)}$ Vero cells were plated at $2 \times 10^{4}$ cells $/ 100 \mu \mathrm{L}$ of $10 \%$ FBS-M199 in the wells of a 96 -well plate (Falcon ${ }^{\circledR} 353072$, Corning) and then cultured for $17 \mathrm{~h}$. Stx 1 (10 pg) and an antibody (varying amount) were mixed in $1 \mathrm{~mL}$ of $10 \%$ FBS-M199, followed by incubation for $1 \mathrm{~h}$ at $37^{\circ} \mathrm{C}$. After replacing the medium with the mixture of Stx1 and an antibody, Vero cells were further cultured for $48 \mathrm{~h}$. Cell viability was measured by means of a colorimetric assay using the Cell Counting Kit- 8 as described. ${ }^{11)}$ Viability was defined as the percentage of the control level (without toxin exposure).

\section{RESULTS}

Stable Expression of a Monomeric Hybrid-IgG/IgA against Stx1B and Its Separation by Gel Filtration CHO-K1 cells were co-transfected with a vector construct harboring the hybrid- $\operatorname{IgG} / \operatorname{IgA} \mathrm{H}$ chain and one harboring the Stx1B-specific IgG1 (D11C6)-associated L chain. Through selection with G418 and hygromycin B followed by limiting dilution cultures, we obtained 121 clones. We screened culture supernatants of the clones as to binding to immobilized Stx1B. We selected two clones that exhibited relatively strong signals, and one clone termed \#3 was used thereafter.

We prepared a $15 \mathrm{~mL}$ of serum-free culture supernatant of clone \#3 (yield: $1.2 \mu \mathrm{g} / \mathrm{mL}$ of $\operatorname{IgA}$ ), followed by concentration to $1 \mathrm{~mL}$ and then separation by gel filtration on a column of Sephacryl S-300. The elution pattern was monitored at $\mathrm{OD}_{280 \mathrm{~nm}}$ and the binding to immobilized Stx1B by ELISA (Fig. 1A). The peak binding was observed around fraction Nos. 39 to 41. We then analyzed each fraction (Nos. 37 to 46) by means of SDS-PAGE (non-reducing) and immunoblotting using anti- $\alpha$ chain antibodies (Fig. 1B). Corresponding to the peak of the binding activity, signals representing a protein, which are recognized by anti- $\alpha$ chain antibodies as a band of 
A

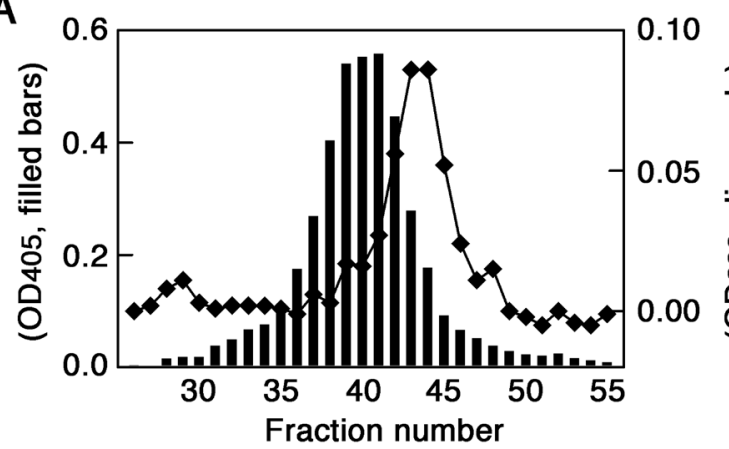

B

Fraction number

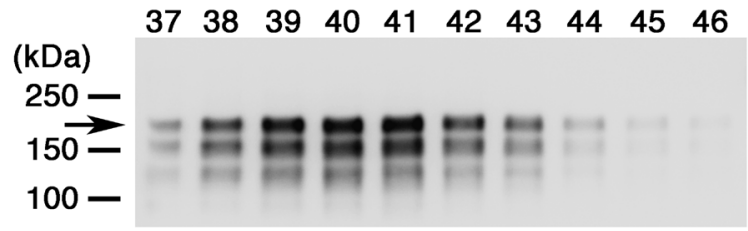

Fig. 1. Stable Expression of a Monomeric Hybrid-IgG/IgA Specific for Stx1B in CHO-K1 Cells

(A) Elution profile of serum-free culture supernatants of CHO-K1 cells double transfected with $\mathrm{H}$ and $\mathrm{L}$ chains of the hybrid-IgG/IgA on a column of Sephacryl S-300. Protein concentrations are plotted as a line graph $\left(\mathrm{OD}_{280 \mathrm{~nm}}\right.$; right axis), and the binding activity of the hybrid-IgG/IgA to immobilized Stx1B is shown as a bar graph $\left(\mathrm{OD}_{405 \mathrm{~nm}}\right.$; left axis) for each fraction $(100 \mu \mathrm{L}$ aliquot; abscissa). (B) SDS PAGE (non-reducing conditions) and immunoblot analysis of each fraction from the Sephacryl S-300 column. The IgA H chain-associated signals in $15 \mu \mathrm{L}$ of each fraction are shown. The positions of molecular weight standards are shown on the left. An arrow points to the intact monomeric hybrid-IgG/IgA.

molecular mass between 150 and $250 \mathrm{kDa}$ (arrow, Fig. 1B), peaked at fraction Nos. 39 to 41. There were several bands with lower molecular masses that appeared in parallel with the band of molecular mass between 150 and $250 \mathrm{kDa}$. This may represent incomplete assembly of the $\operatorname{IgA}$ monomer or partial degradation products.

Stable Expression of a Dimeric Hybrid-IgG/IgA against Stx1B and Its Separation by Gel Filtration CHO-K1 cells were co-transfected with the vector construct harboring the hybrid-IgG/IgA $\mathrm{H}$ chain, that harboring the D11C6-associated $\mathrm{L}$ chain and that harboring the $\mathrm{J}$ chain. Through selection with G418, hygromycin B and zeocin followed by limiting dilution cultures, we obtained 86 clones. We selected clone \#2, which exhibited the strongest binding to immobilized Stx1B.

We prepared a $30 \mathrm{~mL}$ of serum-free culture supernatant of clone \#2 (yield: $0.6-1.2 \mu \mathrm{g} / \mathrm{mL}$ of IgA), followed by concentration to $1 \mathrm{~mL}$ and then separation by gel filtration on the same Sephacryl S-300 column as that used for the separation of the monomeric hybrid- $\operatorname{IgG} / \operatorname{IgA}$. The elution pattern was monitored at $\mathrm{OD}_{280 \mathrm{~nm}}$ and the binding to immobilized Stx1B by ELISA (Fig. 2A). Two peaks of binding were observed around fraction Nos. 36 and 41, respectively. We then analyzed each fraction (Nos. 35 to 41 ) by means of SDS-PAGE (non-reducing) and immunoblotting using anti- $\alpha$ chain antibodies (Fig. 2B). Fraction Nos. 35 and 36 gave a band larger than $250 \mathrm{kDa}$ (Fig. 2B, left arrow), while fraction Nos. 40 and 41 gave a band of molecular mass between 150 and $250 \mathrm{kDa}$ (Fig. 2B, right arrow). Before gel filtration, these two bands were observed (data not shown). The results suggested that the former fractions represent the dimeric hybrid- $\operatorname{IgG} / \operatorname{Ig} \mathrm{A}$ and the latter ones the monomeric hybrid-IgG/IgA.

Characterization of the Hybrid-IgG/IgA Heavy Chain
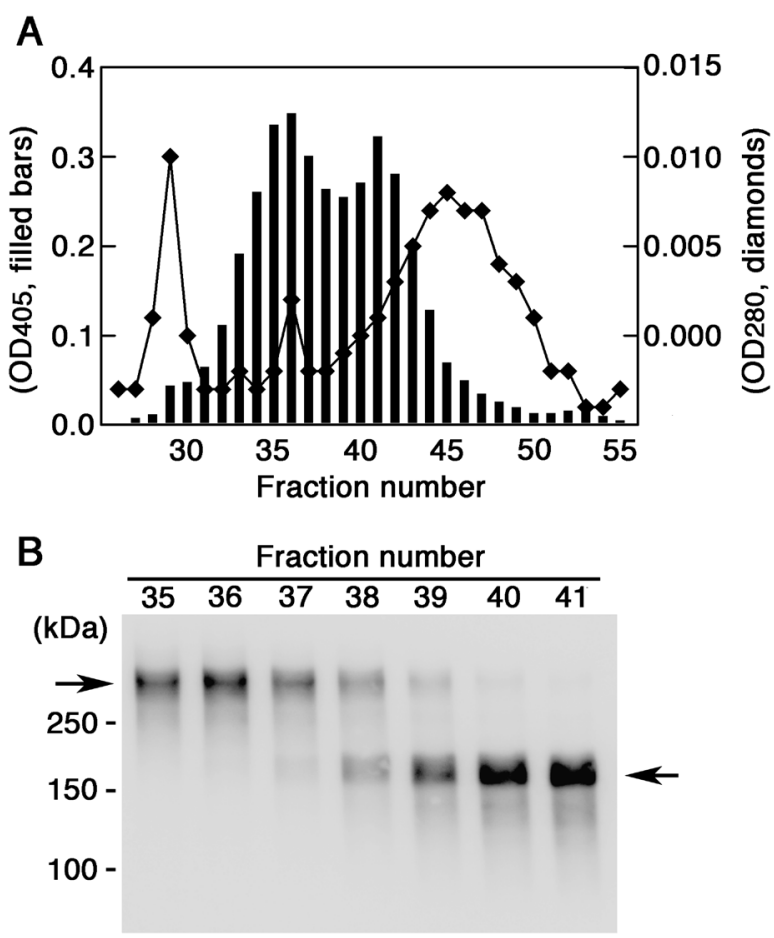

Fig. 2. Stable Expression of a Dimeric Hybrid-IgG/IgA Specific for Stx1B in CHO-K1 Cells

(A) Elution profile of serum-free culture supernatants of CHO-K1 cells triple transfected with H, L and J chains of the hybrid-IgG/IgA on a column of Sephacryl S-300. Protein concentrations are plotted as a line graph $\left(\mathrm{OD}_{280}\right.$; right axis), and the binding activity of the hybrid-IgG/IgA to immobilized Stx1B is shown as a bar graph $\left(\mathrm{OD}_{405 \mathrm{~nm}}\right.$; left axis) for each fraction $(100 \mu \mathrm{L}$ aliquot; abscissa). (B) SDSPAGE (non-reducing conditions) and immunoblot analysis of each fraction from the Sephacryl S-300 column. The IgA H chain-associated signals in $12 \mu \mathrm{L}$ of each fraction (fractions 35 to 41 ) are shown. The positions of molecular weight standards are shown on the left. The right arrow points to the intact monomeric hybrid-IgG/ $\operatorname{Ig} \mathrm{A}$, while the left arrow points to the dimeric one.

A supernatant of clone \#3 (stably expressing $\mathrm{H}$ and $\mathrm{L}$ chains) was subjected to gel filtration to obtain a monomeric $\operatorname{IgG} / \operatorname{Ig} \mathrm{A}$ (fractions 37-43). A supernatant of clone \#2 (stably expressing $\mathrm{H}, \mathrm{L}$ and $\mathrm{J}$ chains) was subjected to gel filtration to obtain a dimeric one (fractions 33-36). After concentration by means of a Vivaspin, the pooled fractions containing the dimeric (Fig. 3, lane 1) or monomeric (lane 2) hybrid-IgG/IgA were subjected to SDS-PAGE and immunoblotting under reducing conditions (Fig. 3). The recoveries of $\operatorname{IgA}$ from culture supernatant to the pooled fractions were $38.5 \%$ and $16.3 \%$ for the monomeric and the dimeric one, respectively. The hybridIgG/IgA $\mathrm{H}$ chains electrophoresed to a position corresponding to a relative molecular mass of 50 to $60 \mathrm{kDa}$ (Fig. 3, left arrowhead). This is slightly smaller than that of mouse $\operatorname{IgA}$ myeloma TEPC 15 (lane 3). This may be due to the difference in domain composition, the hybrid- $\operatorname{IgG} / \operatorname{IgA} \mathrm{H}$ chain containing $\mathrm{VH}, \mathrm{C} \gamma 1, \mathrm{C} \alpha 2$ and $\mathrm{C} \alpha 3$, and the $\operatorname{IgA} \mathrm{H}$ chain containing $\mathrm{VH}, \mathrm{C} \alpha 1, \mathrm{C} \alpha 2$ and $\mathrm{C} \alpha 3$. The specificity for the $\alpha$ chain was verified by the absence of signals from mouse IgG1 myeloma MOPC 21 (lane 4).

Binding of Monomeric and Dimeric IgG/IgA to Immobilized Stx1B Varying concentrations of dimeric or monomeric hybrid $\operatorname{IgG} / \operatorname{IgA}$ in the Sephacryl S-300-pooled fractions were allowed to bind to immobilized Stx1B. The dimers appeared to bind a little better than the monomers did. However, the dose-response curves in response to the total IgA concentrations were situated close to each other (Fig. 4). 


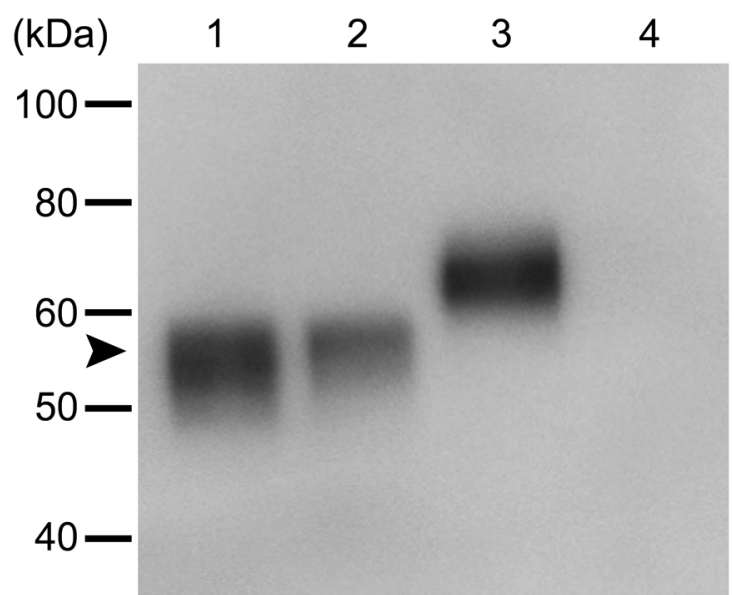

Fig. 3. Immunoblot Analysis of the Heavy Chains of the Hybrid-IgG/ IgA under Reducing Conditions

After fractionation on Sephacryl S-300, samples for dimeric (lane 1) or monomeric (lane 2) hybrid-IgG/IgA were separated by SDS-PAGE $(12 \%$ gel, reducing conditions), and then analyzed by immunoblot analysis using anti-IgA $\mathrm{H}$ chains. Each lane contains $20 \mathrm{ng}$ of $\operatorname{IgA}$ as determined by sandwich ELISA. As controls, $20 \mathrm{ng}$ of IgA myeloma TEPC 15 (lane 3) and IgG1 myeloma MOPC 21 (lane 4) were analyzed. The positions of molecular weight standards are shown on the left. An arrowhead points to the heavy chain of hybrid-IgG/IgA

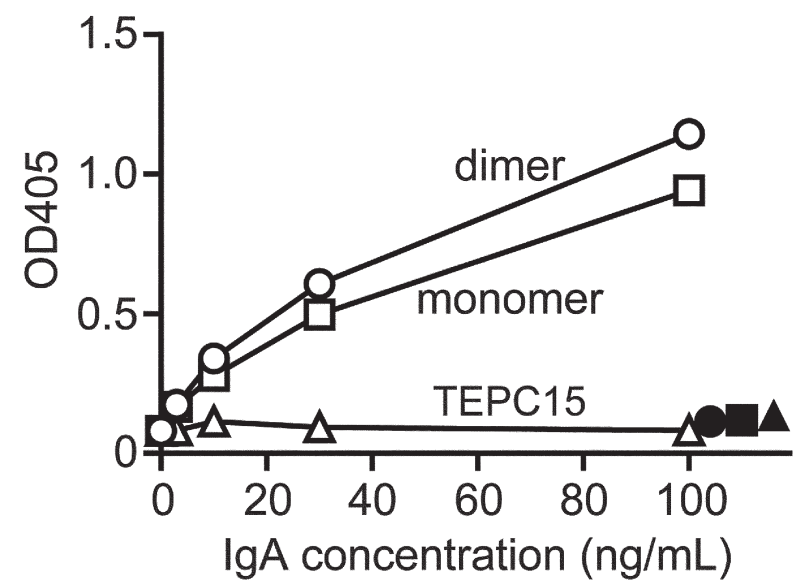

Fig. 4. Binding of Monomeric and Dimeric Hybrid-IgG/IgA to Immobilized Stx1B

Sephacryl S-300-pooled samples for dimeric (open circles) or monomeric (open squares) hybrid-IgG/IgA, or purified IgA myeloma TEPC 15 (open triangles) were allowed to bind to immobilized Stx1B (500 ng/well). The binding was detected with HRP-goat anti-mouse IgA by means of ELISA in response to IgA concentration (abscissa). Data are expressed as means of triplicate determinations. Error bar (S.D.) are too short to appear. Background binding without immobilized Stx1B was shown by respective filled symbols. Only the results at $100 \mathrm{ng} / \mathrm{mL}$ are displayed for clarity but no binding was seen at other concentrations.

An IgA myeloma TEPC 15 did not bind to Stx1B. The hybrid $\mathrm{IgG} / \operatorname{Ig} \mathrm{A}$ did not bind to the wells without immobilized Stx1B.

Toxin Neutralization by the Monomeric and Dimeric Hybrid-IgG/IgA In each hybrid-IgG/IgA sample, the concentration of assembled immunoglobulins was determined by sandwich ELISA. Thus, the ELISA was performed using a format whereby immunoglobulins with $\mathrm{H}$ chains were captured and only those with L chains can give rise to signals.

First, we examined whether the cytotoxicity to Vero cells on treatment with $10 \mathrm{pg} / \mathrm{mL}$ of Stx 1 could be blocked by $1 \mu \mathrm{g} /$ $\mathrm{mL}$ of an antibody (Fig. 5A). Upon $48 \mathrm{~h}$ cell culture with Stx 1 , a $50 \%$ reduction in the viability was observed with an 3-(4,5-dimethylthiazol-2-yl)-2,5-diphenyltetrazolium bromide (MTT)-like assay that reflects reduced nicotinamide adenine
A

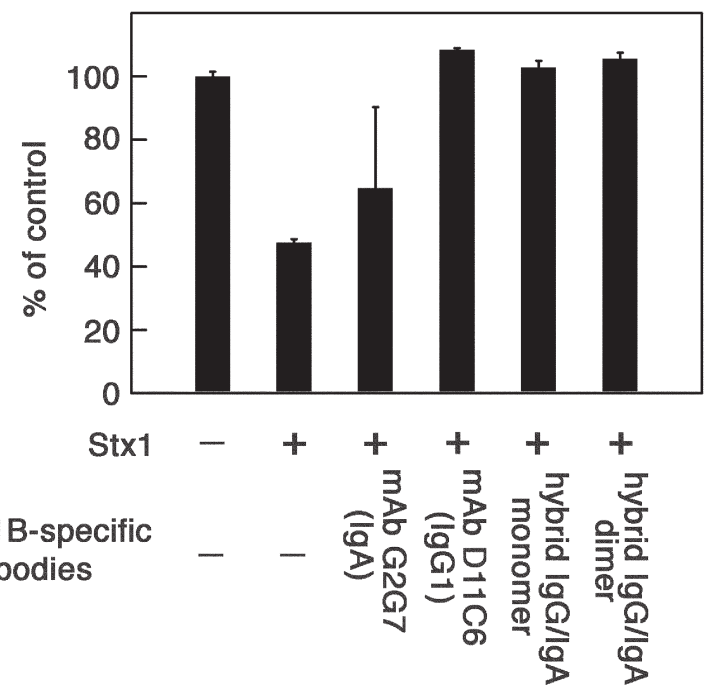

B

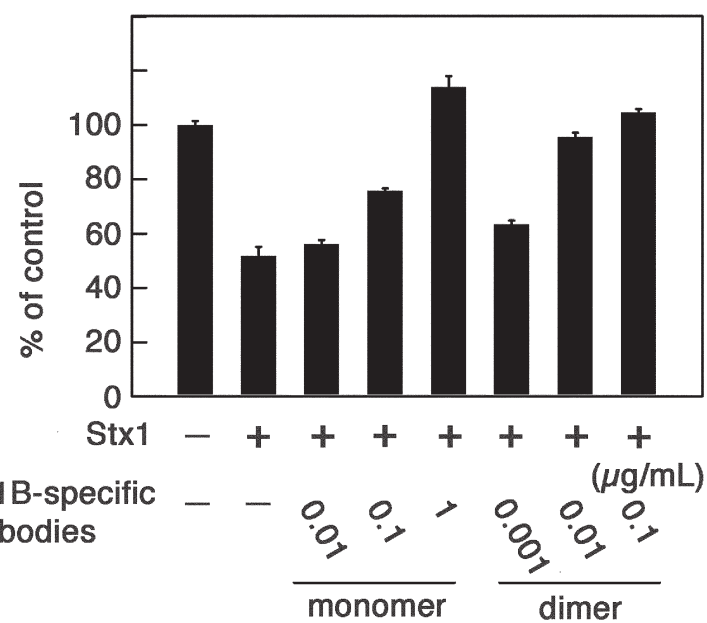

Fig. 5. Toxin Neutralization by the Hybrid-IgG/IgA

Stx 1 holotoxin and one of the antibodies (specified at the bottom) were preincubated for $1 \mathrm{~h}$. The mixture was added to Vero cells, followed by culture for $48 \mathrm{~h}$. Cell viability was determined primarily based on the mitochondrial activity. The values shown are relative to that in the absence of Stx1. (A) Stx1 was preincubated with $1 \mu \mathrm{g} / \mathrm{mL}$ of each antibody. (B) Stx1 was pre-incubated with varying concentrations of the monomeric or dimeric hybrid- $\operatorname{IgG} / \mathrm{IgA}$. The bars represent the means \pm standard deviations of triplicate determinations.

dinucleotide (phosphate) (NAD $(\mathrm{P}) \mathrm{H})$-dependent cellular oxidoreductase activity. An Stx1B-specific IgA mAb, G2G7, did not significantly improve the viability, as expected. ${ }^{11)}$ On the other hand, an Stx1B-specific IgG mAb, D11C6, completely inhibited the cytotoxicity, as also expected. ${ }^{11)}$ Since the hybrid-IgG/IgA utilizes the variable regions of D11C6, toxin neutralization activity was expected. Both the monomeric and dimeric hybrid-IgG/IgA inhibited cytotoxicity toward Vero cells.

Second, we varied concentrations of the hybrid- $\operatorname{IgG} / \operatorname{Ig} \mathrm{A}$ to evaluate the relative efficacy (Fig. 5B). For the monomeric one, complete inhibition at $1 \mu \mathrm{g} / \mathrm{mL}$ but incomplete inhibition at $0.1 \mu \mathrm{g} / \mathrm{mL}$ were observed. In contrast, complete inhibition was seen at 0.01 to $0.1 \mu \mathrm{g} / \mathrm{mL}$ for the dimeric one, but it was not effective at $0.001 \mu \mathrm{g} / \mathrm{mL}$. These results suggested that the dimeric hybrid-IgG/IgA is more than 10-times more effective compared with the monomeric one on a weight basis. 


\section{DISCUSSION}

The major objective of this study is the production of cell lines expressing monomeric or dimeric recombinant IgA against Stx1B to test their toxin neutralizing activity. To obtain a sufficient and constant supply of the recombinant IgA against Stx1B, we stably expressed immunoglobulin genes in $\mathrm{CHO}-\mathrm{K} 1$ cells. The hybrid-IgG/IgA utilizes variable regions, both $\mathrm{H}$ and $\mathrm{L}$ chains, from an $\mathrm{IgG} 1 \mathrm{mAb}$ that exhibits remarkable toxin neutralization activity. Because the $\mathrm{H}$ chain constant region was from an $\operatorname{IgA} \mathrm{mAb}$, it can be dimerized through a J chain. ${ }^{6}$ When co-expressed with $\mathrm{J}$ chains in $\mathrm{CHO}-\mathrm{K} 1$ cells, the dimeric hybrid-IgG/IgA was observed along with the monomeric one. Thus, we needed to use sizeexclusion chromatography to prepare a dimeric hybrid-IgG/ IgA sample that is devoid of monomeric one.

The CHO-K1 cells transfected with $\mathrm{H}$ and $\mathrm{L}$ chains only produced monomers without dimers as revealed by immunoblotting analysis after SDS-PAGE under non-reducing conditions (Fig. 1). In contrast, $\mathrm{CHO}-\mathrm{K} 1$ cells transfected with $\mathrm{H}, \mathrm{L}$ and $\mathrm{J}$ chains produced monomers and dimers, but the dimers were isolated by size-exclusion chromatography essentially being devoid of monomers (Fig. 2). Taking advantage of these two cell lines, we could assess the biological activity of the dimeric hybrid-IgG/IgA in comparison with those of the monomeric one.

The dimers devoid of monomers were able to neutralize toxin activity with more than tenfold efficacy on a weight basis. In contrast, it appears that only a few difference between monomers and dimers in the binding activity to immobilized Stx1B, when one compares the result of each fraction on gelfiltration (Figs. 2A, B). To confirm this, dose-response curves were compared between the monomer and dimer preparations in the ability of binding to immobilized Stx1B. The binding of dimers appeared to be a little more efficient, but the difference was only a small one. It may be that the dimeric $\operatorname{IgG} / \operatorname{Ig}$ A with tetravalent binding sites is more effective in the lattice formation with Stx1 in solution. The tetravalent nature of binding sites may add only a small effect to the binding of antibodies to immobilized antigens on an ELISA plate.

Upon transient expression of the dimeric hybrid-IgG/IgA in COS-1 cells, the relative molecular mass of the hybrid-IgG/ $\operatorname{IgA~} \mathrm{H}$ chain was smaller than that of $\operatorname{IgA}$ myeloma TEPC 15. ${ }^{12)}$ This was also observed in the present system using CHO-K1 cells.

We did not examine the toxin neutralization activity of the sample from transiently expressed COS-1 cells because we could not obtain sufficient amounts of antibodies. Recently, we succeeded in producing a dimeric hybrid-IgG/IgA in a plant system involving Arabidopsis thaliana. ${ }^{14)}$ In this plant, there are also monomers, and several incomplete IgA and fragments. Although plantibodies are able to neutralize toxins, we could not determine the relative efficacy of intact $\mathrm{dIg} \mathrm{A}$ as to the toxin neutralization. In the present study, we directly demonstrated that the dimeric form of $\operatorname{IgA}$ produced in CHO-K1 cells efficiently neutralizes Stx1.

To prevent infectious diseases, a vaccine strategy that leads to the production of IgA on the mucosal surface is a possibility. In this case, one needs an efficient and safe adjuvant to overcome peripheral tolerance for the initiation of immune responses against given antigens. Furthermore, probably due to the abundant commensal bacteria on the gut mucosal surface, it is not straightforward to produce SIgA specific for target antigens. Thus, many IgA may be directed to commensal bacterial species rather than specific antigens of which neutralization is required. Preformed SIgA against pathogens will become a valuable strategy in place of vaccination.

SIgA are produced through transepithelial transport of dIgA in vivo. ${ }^{8)}$ That is, $\mathrm{d} \operatorname{Ig} \mathrm{A}$ is the product of $\mathrm{B}$ cells whereas $\mathrm{SC}$ is the product of epithelial cells. In addition, the expression of the $\mathrm{J}$ chain together with the $\mathrm{H}$ and $\mathrm{L}$ chains is essential for SIgA because monomeric IgA can not form SIgA.,15) Some earlier studies demonstrated that SIgA could be produced when SC was co-expressed in $\mathrm{CHO}$ cells, however, the efficiency of the formation of SIgA was not clearly demonstrated. ${ }^{16)}$ Alternatively, in vitro reconstitution is another possibility for obtaining SIgA. ${ }^{17)}$ In either case, the production of dIgA of enough amount and with reasonable purity is essential to produce SIgA and to test its effect in vivo. We are currently in progress to establish protein purification scheme for the dimeric $\operatorname{IgG} / \operatorname{IgA}$.

In conclusion, we stably expressed dimeric $\operatorname{IgG} / \operatorname{IgA}$ specific for Stx1B in CHO-K1 cells. The dimers, separated by size-exclusion chromatography, could efficiently neutralize toxin activity. The dimers will be useful for the preparation of SIgA. SIgA produced by cultured animal cells will serve as useful standards for the SIgA produced by plants we have developed.

Acknowledgments This work was partly supported by a Grant-in-Aid for Scientific Research (C) [No. 16590055], a Grant-in-Aid for Challenging Exploratory Research [No. 23659067, 25670063], and by research funding for the Global COE Program from the Japan Society for the Promotion of Science.

\section{REFERENCES}

1) Kaper JB, Nataro JP, Mobley HL. Pathogenic Escherichia coli. Nat. Rev. Microbiol., 2, 123-140 (2004).

2) Kotloff KL, Winickoff JP, Ivanoff B, Clemens JD, Swerdlow DL, Sansonetti PJ, Adak GK, Levine MM. Global burden of Shigella infections: implications for vaccine development and implementation of control strategies. Bull. World Health Organ., 77, 651-666 (1999).

3) Paton JC, Paton AW. Pathogenesis and diagnosis of Shiga toxinproducing Escherichia coli infections. Clin. Microbiol. Rev., 11, 450-479 (1998).

4) Stein PE, Boodhoo A, Tyrrell GJ, Brunton JL, Read RJ. Crystal structure of the cell-binding B oligomer of verotoxin-1 from E. coli. Nature, 355, 748-750 (1992).

5) Hovde CJ, Calderwood SB, Mekalanos JJ, Collier RJ. Evidence that glutamic acid 167 is an active-site residue of Shiga-like toxin I. Proc. Natl. Acad. Sci. U.S.A., 85, 2568-2572 (1988).

6) Woof JM, Kerr MA. The function of immunoglobulin A in immunity. J. Pathol., 208, 270-282 (2006).

7) Brandtzaeg P. Function of mucosa-associated lymphoid tissue in antibody formation. Immunol. Invest., 39, 303-355 (2010).

8) Corthésy B. Multi-faceted functions of secretory IgA at mucosal surfaces. Front. Immunol., 4, 185 (2013).

9) Imai $Y$, Nagai R, Ono Y, Ishikawa T, Nakagami H, Tanikawa T, Kurohane K. Production of secretory immunoglobulin A against Shiga toxin-binding subunits in mice by mucosal immunization. Infect. Immun., 72, 889-895 (2004). 
10) Imai $Y$, Ishikawa $T$, Tanikawa $T$, Nakagami $H$, Maekawa $T$, Kurohane K. Production of IgA monoclonal antibody against Shiga toxin binding subunits employing nasal-associated lymphoid tissue. $J$. Immunol. Methods, 302, 125-135 (2005).

11) Tanikawa $T$, Ishikawa $T$, Maekawa $T$, Kurohane $K$, Imai Y. Characterization of monoclonal immunoglobulin $\mathrm{A}$ and $\mathrm{G}$ against Shiga toxin binding subunits produced by intranasal immunization. Scand. J. Immunol., 68, 414-422 (2008).

12) Tobisawa $Y$, Maruyama T, Tanikawa $T$, Nakanishi K, Kurohane K, Imai Y. Establishment of recombinant hybrid-IgG/IgA immunoglobulin specific for Shiga toxin. Scand. J. Immunol., 74, 574-584 (2011).

13) Miyashita S, Matsuura Y, Miyamoto D, Suzuki Y, Imai Y. Development of recombinant B subunit of Shiga-like toxin 1 as a probe to detect carbohydrate ligands in immunochemical and flowcytometric application. Glycoconj. J., 16, 697-705 (1999).
14) Nakanishi K, Narimatsu S, Ichikawa S, Tobisawa Y, Kurohane K, Niwa Y, Kobayashi H, Imai Y. Production of Hybrid-IgG/IgA plantibodies with neutralizing activity against Shiga toxin 1. PLoS ONE, 8, e80712 (2013).

15) Johansen FE, Braathen R, Brandtzaeg P. The J chain is essential for polymeric Ig receptor-mediated epithelial transport of IgA. J. Immunol., 167, 5185-5192 (2001).

16) Johansen FE, Natvig Norderhaug I, Røe M, Sandlie I, Brandtzaeg P. Recombinant expression of polymeric IgA: incorporation of J chain and secretory component of human origin. Eur. J. Immunol., 29, 1701-1708 (1999).

17) Longet S, Miled S, Lötscher M, Miescher SM, Zuercher AW, Corthésy B. Human plasma-derived polymeric IgA and IgM antibodies associate with secretory component to yield biologically active secretory-like antibodies. J. Biol. Chem., 288, 4085-4094 (2013). 